PHYSICAL REVIEW SPECIAL TOPICS - PHYSICS EDUCATION RESEARCH 6, 029901(E) (2010)

\title{
Editorial Note: Patterns, correlates, and reduction of homework copying [Phys. Rev. ST Phys. Educ. Res. 6, 010104 (2010)]
}

David J. Palazzo, Young-Jin Lee, Rasil Warnakulasooriya, and David E. Pritchard (Received 28 July 2010; published 3 August 2010)

DOI: 10.1103/PhysRevSTPER.6.029901

PACS number(s): 01.40.Fk, 01.40.Di, 01.40.-d, 01.50.H-, 99.10.Np

The authors had a financial connection with Mastering Physics. All funding sources supporting the work and all institutional or corporate affiliations should have been disclosed in the published article. We require authors of research articles at the time of submission to disclose to the APS Editorial Office any potential conflict of interest, financial or otherwise. 